\title{
Highly Recommended and Poorly Used: English and Spanish Science Teachers' Views of Inquiry-based Learning (IBL) and its Enactment
}

\author{
Marta Romero-Ariza 1, Antonio Quesada 1, Ana Maria Abril 1, Peter Sorensen 2, \\ Mary Colette Oliver ${ }^{2 *}$ \\ 1 University of Jaen, SPAIN \\ 2 University of Nottingham, UK
}

Received 27 February 2019 • Revised 24 May 2019 - Accepted 27 May 2019

\begin{abstract}
Inquiry pedagogies provide opportunities to meet learning outcomes linked to developing scientific literacy. Within a European project intended at promoting Inquiry Based Learning (IBL), this paper presents quantitative and qualitative data about teachers' views of IBL and its enactment in England and Spain. Results show that teachers in both countries hold positive views based on benefits to students and science learning and perceive important systemic and personal barriers to the successful implementation, even after decades of political efforts. Teachers express frustration with the lack of time, teaching resources, classroom management and the demands of curriculum delivery, assessment and accountability. There is an emphasis on hands-on activities and students' motivation but no stress on cognitive and epistemic aspects, showing views not well aligned with current understanding of the type of inquiry that best support learning. Implications for research and practice suggest that there is still a need to expand knowledge about how to support teachers in making the most of this pedagogy.
\end{abstract}

Keywords: inquiry, scientific literacy, scientific practices, teachers' views, teacher professional development

\section{INTRODUCTION}

The purpose of science education has been articulated as two-fold: to 'educate students both about the major explanations of the material world that science offers and about the way science works' (Osborne \& Dillon, 2008, p. 8). Thus, it is important to develop the skills, understanding and dispositions required in the next generation of scientists; it is also imperative, improving scientific literacy in the general population, to equip, future citizens with the skills and understanding of scientific principles to make good choices about their future lives, work, health and care of the environment. International assessments and surveys such as the Programme of International Student Assessment (PISA), Trends in Mathematics and Science Study (TIMSS), and the Relevance of Science Education (ROSE) have focused our attention on the performance of children and young people across the globe. In 2015, scientific literacy was once more the focus of the PISA assessments in OECD countries. A scientifically literate young person is, according to PISA, able to 'engage in reasoned discourse about science and technology' (OECD, 2017, p. $15)$ thus requiring competencies to explain phenomena, evaluate and design scientific inquiry and interpret data and evidence scientifically. Inquiry-Based Learning (IBL), also referred to as inquiry-based teaching or InquiryBased Science Education (IBSE), is the pedagogy promoted as a key approach to meet these learning outcomes.

Inquiry-based teaching has become part of the lexicon in Europe, receiving policy support, funding and promotion from the EU. This followed the publication of the Rocard report (European Commission, 2007) recommending that 'the introduction of inquiry-based approaches in schools ... should be actively promoted' ( $\mathrm{p}$.

(C) 2020 by the authors; licensee Modestum Ltd., UK. This article is an open access article distributed under the terms and conditions of the Creative Commons Attribution License (http://creativecommons.org/licenses/by/4.0/).

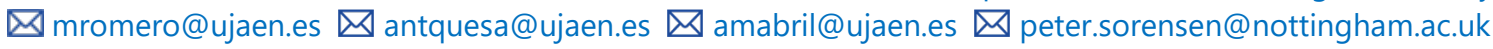




\section{Contribution of this paper to the literature}

- Pre-service and in-service Spanish and English science teachers' views and experiences of inquiry are presented here using quantitative and qualitative data from a European Union funded project.

- Teachers shared similar views about the benefits of IBL but their enthusiasm was tempered by expectations to address national assessment and curriculum. They claimed for consistent systemic support and specific training and teaching resources.

- Even those with sophisticated views of IBL, failed to see inquiry as the optimal approach for the development of evidence-based explanations and the promotion of scientific literacy as the ability to engage in reasoned discourse about science and technology.

17), giving rise to a concerted EU commitment to IBL projects (such as Mathematics and Science in Life, MASCIL). The various projects' webpages reinforce the position that the 'science education community agrees that pedagogical practices based on IBSE methods are more effective (https://www.uibk.ac.at/botany/research/learning/inquire). For example, 'inquiry-based learning is a concept which underlines the importance of students engaging into meaningful hands-on science experiences' (http:/ / www.mascil-project.eu/project/objectives) and there is a shared understanding that IBL is typified when students pose questions, plan and investigate. Such positions are supported in the literature (for example, Engel, Euler \& Mass, 2013; Lederman, Lederman, \& Antink, 2013). A more nuanced message about the roles of teachers' guidance and types of inquiry have been published in the research synthesis and meta-analyses (Furtak, Seidel, Iverson, \& Briggs, 2012; Lazonder \& Harmsen, 2016; Minner, Levy, \& Century, 2010).

Our research examines the views of teachers in England and Spain for implementing IBL, drawing on data collected from a survey associated with a European project, together with interviews and focus groups of teachers at various stages of their careers. The purpose of the research presented in this paper was to determine the teachers' views toward inquiry in the science classroom. More specifically, the research questions were:

1. What are science teachers' views of inquiry in England and Spain?

2. What are science teachers' views and experiences of inquiry as enacted in their classrooms in England and Spain?

3. What are the barriers or constraints to successful inquiry implementation?

Before discussing the results, we draw on the specialised literature in order to frame our study within the research evidence about IBL, teacher's views and reported practices of inquiry and professional development in this field.

\section{Background to the Study}

Arguments for the adoption of IBL can be traced back over many years. An inquiry-based teaching approach may support and deepen learning of scientific concepts (Minner et al., 2010), overcome misconceptions as part of constructivist teaching and learning approaches (Ariza, Aguirre, Quesada, Abril \& García, 2016; Önder, Şenyiğit, \& Silay, 2018), develop curiosity, engagement and interest in science (McConney, Oliver, Woods-McConney, Schibeci, \& Maor, 2014), promote an understanding of the nature of science and what scientists do (Lederman et al., 2013) and develop future citizens who are able to make informed decisions about their lives and those of others (Lee \& Brown, 2018).

It is not clear, though, whether inquiry is limited to procedural aspects of learning and teaching science, where the 'the scientific method continues to reinforce a kind of cultural lore about what it means to participate in inquiry' and where there is little 'epistemic framing relevant to the discipline' (Windschitl, Thompson, \& Braaten, 2008, p.941). Teachers in primary schools in the Netherlands have reported difficulty 'in guiding pupils through the process of inquiry, for example, regarding the formulation of a research question' (van Uum, Verhoeff \& Peeters, 2016, p.451). How do teachers help students 'connect' the process, the investigative, the 'doing' of science to the larger body of knowledge as' prime catalysts for new predictions, insights and phenomena... not simply 'endproducts' of inquiry'? (Windschitl et al., 2008, p. 944). In examining the evidence during their practical work, students can develop an understanding of how 'scientific knowledge is generated' (Furtak, et al., 2012, p. 305) attending to the epistemic domain (Duschl \& Bybee, 2014; Osborne, 2014; van Uum et al., 2016; Windschitl et al., 2008). In a similar vein, the European report 'Science Education for Responsible Citizenship' defines inquiry as 'a complex process of sense-making and constructing coherent conceptual models where students formulate questions, investigate to find answers, build new understandings, meanings and knowledge, communicate their learning to others and apply their learning productively in unfamiliar situations' (European Commission, 2015, p. 68). 


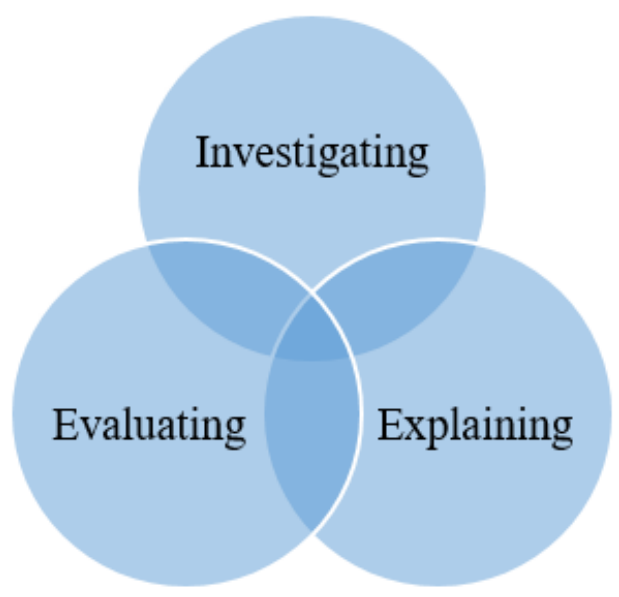

Figure 1. Spheres of Activity Model (taken from NRC, 2012)

In the US, a change in emphasis from 'inquiry' to 'scientific practices' is evident in the Framework for K-12 Science Education: Practices, Crosscutting Concepts, and Core Ideas (2012) published by the National Research Council. A model of three 'spheres of activity to include investigating, evaluating and developing explanations and solutions' (NRC, 2012, p. 45) to reflect the practices of scientists and engineers and this model has been used to advocate a broader understanding of inquiry (Capps, Shemwell, \& Young, 2016).

This three spheres model (Figure 1) places the critical evaluation of ideas as the key dimension connecting evidence and explanatory theories. There is a greater emphasis on science as a mainly semantic activity, with the subsequent implications for the role of argumentation and modelling in science education. Osborne (2014) discussed the rationale underpinning the model and the way it created a greater clarity of goals, about what students should experience and learn. Using the NRC Framework, Duschl and Bybee identified the challenge of 'coupling the learning of content with engagement of practices' (2014, p.3) presenting one approach in unpacking one practice, of 'Planning and Carrying out Investigations'. Such models have the potential to help clarify both the purposes of inquiry, scientific practices and the attendant pedagogical approaches.

\section{Types of Inquiry}

Crawford (2014, p. 516) reflects the views of many working in the field of inquiry in noting that it is 'advocated and expected yet surprisingly rare and enigmatic'. The variety of uses and meanings include 'an instructional approach, curriculum materials and a way for students to learn science' (Rönnebeck, Bernholt, \& Ropohl, 2016, p. 162). There is a wealth of literature discussing the types of inquiry and the efficacy of particular approaches. Literature reviews identify different dimensions of inquiry-based teaching. For example, one dimension is concerned with the particular types of activities the students engage with, procedural knowledge (OECD, 2017). This aspect reflects the range of activities such as 'repeating measurements to minimise error and reduce uncertainty, the control of variables, and standard procedures for representing and communicating data' (OECD, 2017, p.21). The second dimension of inquiry is concerned with the level of guidance provided by the teacher (Furtak, et al., 2012; Rönnebeck et al., 2016). Linked to these dimensions are issues concerned with the purposes of IBL. Abd-El-Khalick et al. (2004, p. 398) have characterised these as Inquiry as means (or inquiry in science), with science content as the instructional goal, and Inquiry as ends (or inquiry about science), where inquiry is the instructional goal (students learn about the nature of science (NOS) and relevant inquiry skills). They note that the prevailing views characterise practices as content-process and discovery-inquiry and argue for a move to a more evidence-explanation approach to inquiry-based teaching and learning. Given the many dimensions associated with characterising IBL and its purposes, studies of efficacy face multiple problems. This has led to some very different claims concerning impact. Alfieri, Brooks, Aldrich, and Tenenbaum's (2011) reported that "unassisted discovery does not benefit learners, whereas feedback, worked examples, scaffolding, and elicited explanations do" (p. 1). To shed light on the effects of the types of instruction and student learning, Furtak et al. (2012) developed a framework to categorise the different aspects of inquiry in a meta-analysis of inquiry-based teaching. They distinguished between the "cognitive features of the activity and degree of guidance given to students" (p. 300) concluding that epistemic activities had the highest mean effect sizes compared with other forms of inquiry, namely, procedural, and social. Furthermore, they pointed out "studies involving teacher-led activities had mean effect sizes about .40 larger than those with student-led conditions" (p. 300). These findings support Lazonder and Harmsen's (2016) meta-analysis, "that guidance has a significant positive effect on inquiry learning activities, performance success, and learning outcomes" (p.23) and reinforce the views of Kirschner, Sweller, and Clark (2006). 
Hattie's (2009) large-scale meta-analysis demonstrated low impact for inquiry in general, but medium to high impact for approaches involving an emphasis on questioning, metacognition and collaborative and cooperative learning, which many would view as key components of IBL approaches. In a review comparing different teaching approaches, Kirschner et al. (2006) found that 'minimally guided instruction is less effective and less efficient than instructional approaches that place a strong emphasis on guidance of the student learning process' (p. 75).

Analysis of the PISA 2006 and 2015 data further illustrates some of the issues here, as the 15-year old students reporting the highest levels of inquiry in their classrooms in the PISA 2006 and 2015 questionnaires also had lower levels of scientific literacy or achievement (McConney et al., 2014; Jerrim, Oliver, \& Sims, 2019). This finding highlights the importance of being clearer about the characteristics of IBL that allow both higher engagement and positive learning outcomes. Minner et al. (2010) identified particular aspects of IBL that supported students' conceptual understanding. In particular, the review suggested that conceptual understanding was more likely to be achieved through use of "teaching strategies that actively engage students in the learning process through scientific investigations" (p. 474) with emphasis on the "active thinking and drawing conclusions from the data" (p. 474). In summary, a trend is developing to focus more of 'the science as argument and explanation and less on science as exploration and experiment' (Kawalkar \& Vijapurkar, 2013, p. 2005) and researching the conditions under which inquiry learning can be effective.

\section{Teachers' Views and Experiences with Inquiry}

Teachers' views, perceptions and beliefs are terms used somewhat interchangeably and we use the term 'teacher views' throughout this paper to reflect the more direct interrogation of their ideas, experiences of enactment and reflections of IBL. Teacher's views play a key role on teaching practices, and persistence, acceptability of innovation and potential change (Donnell \& Gettinger, 2015). These are malleable, with experiences of research supporting revision of beliefs and attitudes towards teaching science as inquiry (Herrington, Bancroft, Edwards, \& Schairer, 2016, p. 183). Glackin (2016) showed that teachers, who successfully implemented an innovation of learning outside the classroom, were those generally holding social constructivist beliefs. Such congruence between teachers' beliefs and practices is not always so closely aligned. Buehl and Beck (2015) found that teachers' espoused beliefs were not present in their enacted practices and that teachers engaged in practices they claimed that they do not support. In this line, Lebak (2015) shows that initially espoused beliefs were often inconsistent with enacted practice and some beliefs emerged as more salient than others for influencing practice. That such beliefs somehow compete with each other is not unique and these are acknowledged as being "highly idiosyncratic" (Herrington et al., 2016, p. 185). Hutner and Markham (2016) report that teachers can (and do) "hold multiple sets of representations that influence their cognition related to teaching" (p. 51). Evidence over the years has continued to identify a gap between their declared beliefs and actions and "even some of the best teachers struggle to enact reform-based teaching" (Capps \& Crawford, 2013, p. 498). Teachers articulated conflicting beliefs about inquiry with respect to the aims of meeting the curriculum and assessment demands, barriers and challenges in using a more inquiry approach (Krämer, Nessler, \& Schlüter, 2015) as well as promoting independent and deep learning. Interviews and observations of 44 beginning science teachers in the US confirmed that these teachers enacted teacher-centred forms of inquiry in their classes, and spoke about "features of scientifically oriented questions and priority to evidence" but little of the activities associated with connecting data to evidence, or explanation of evidence in their discussion about inquiry (Ozel \& Luft, 2013, p. 312).

Teachers reported that inquiry was "more as a process about which students should learn and in which students should participate than as a vehicle for learning science content as teachers' reports focus more on the hands-on aspects of inquiry than on the sense-making aspects" (Asay \& Orgill, 2010, p. 76; Schwarz et al., 2008). Pre-service teachers tend to focus on the "investigative dimensions at the expense of explanation-construction" aspects of inquiry (Forbes \& Davies, 2010, p. 822). A gap seems to exist between the procedural (hands-on, investigative) and more cognitive (explanatory) aspects of inquiry. Surveys and interviews with science teachers in the US show that most teachers do not have "well-structured inquiry knowledge, despite reporting very frequent enactment" (Capps et al., 2016, p. 954).

The works discussed above show the complex relationship between teachers' views, previous experiences and practices. As science educators, we need to understand the challenges in promoting and enacting of inquiry pedagogies. Are teachers aware of the debate about different kinds of inquiry and 'good' IBL practices? This study explores the experience of pre-service and in-service teachers in England and Spain. 


\section{METHOD}

We address our research questions through a mixed methods approach combining quantitative data from a survey with qualitative data from interviews and focus group discussions with selected teachers from England and Spain. This research approach has the advantage of enabling the investigation of more complex research questions and to obtain a richer picture, allowing the combination of strengths of quantitative and qualitative approaches and overcoming their particular weaknesses (Creswell \& Plano Clark, 2011).

\section{Instruments}

The instrument used for the survey was the one developed for the baseline study of the European project MASCIL. It consists of a four-point Likert-type questionnaire reflecting level of agreement with 77 items. Items were distributed into 6 different dimensions or sub-scales with Cronbach's alphas ranging from 0.89 to 0.68 . The instrument was administered to 1132 teachers of thirteen European countries and information about its validity and consistency may be found in Maaß and Engeln (2016). For the purpose of this study with draw on data from the English and the Spanish samples, extracting information about the sub-scales related to orientation to and use of IBL, as well as barriers and obstacles for the implementation into daily teaching.

To develop a richer picture of teachers' views of IBL, we conducted a series of four exploratory interviews in England and two focus group discussions in Spain with selected pre-service and in-service teachers in both countries. The number of interviews and focus group discussions was determined by research needs to collect enough evidence to address the research questions.

The international research team agreed on a common set of initial open questions to guide interviews and focus group discussions. However, new themes arose, and interviewers introduced other questions when necessary, to get a better understanding of key issues. Interviews and group discussions lasted between 45 minutes and one and a half hours. The duration depended on the time required to cover the previously prepared questions and the achievement of a good understanding of teachers' responses.

\section{Sampling}

Fifty-three English science teachers (45\% female) and 76 Spanish teachers (55\% female) completed the survey about their orientation to and use of IBL and the difficulties perceived for its implementation. This sample from the MASCIL baseline study was considered representative of the kinds of teachers who joined professional development courses about IBL in both England and Spain. Hence, it is likely that such teachers are supportive of moves to adopt IBL approaches.

Participants for the qualitative study in both countries involved pre-service and in-service teachers who were selected purposefully (Charmaz \& McMullen, 2011), as individuals with previous knowledge and experiences in IBL, or at least, a personal motivation for innovation in science education.

In England four teachers were interviewed, one female and one male experienced, committed to innovative approaches and two student teachers working with them (one female and one male). One of the experienced teachers was Head of Science and the second was a lead teacher and mentor. The student teachers both had similar biological science backgrounds.

In Spain, six in-service teachers (three females) with a teaching experience ranging from 10-30 years were involved in one session focus group discussion on IBL (FGD1). Additionally, five pre-service teachers (four males) aged 21-23, who had just finished their university degree to become schoolteachers were engaged in other one session focus group discussion on the same topic (FGD2). The student teachers had experience of 25 weeks of practice at schools during their education at the university.

\section{Data Collection and Data Analysis}

Quantitative data were collected through the questionnaire used for the baseline study of the project MASCIL and analysed using SPSS v.19.0. Cronbach's alphas were calculated in order to evaluate the internal consistency of the sub-scales and the instrument reliability (see instrument description). Two-factor ANOVA was used to test for IBL-orientation differences among the participant countries, along with analysis of variance indicating a small significant effect of the country on the orientation towards IBL, $F(12,1116)=6.16$, $p<.001$ (see more information in Maaß \& Engeln, 2016). 
Interviews and group discussions were audio-recorded, transcribed and analysed by two independent researchers using MAXQDA 12.1.0. An inductive approach was used for identifying patterns and common themes and for agreeing on a particular set of categories and sub-categories. Evaluators went through three iterative cycles of analysis to ensure internal consistency in the coding, reaching an interrater reliability with an overall Kappa of 0.89 .

\section{RESULTS}

We present a list of summary findings, which are then elaborated and discussed in relation to the literature and context.

1. Teachers' views of IBL are generally positive in both samples, that IBL benefits students, increasing student motivation and improves science teaching. Very few teachers from both samples selected options that opposed the use of IBL in their science lessons.

2. In the focus groups, teachers identified aspects of IBL that were important: the use of open-ended tasks and the nature of collaboration in the classroom.

3. When teachers reflected on their experiences of enacting IBL, they spoke of this approach motivating, encouraging student engagement with the potential to provide relevant and authentic tasks and the 'surprise' of students' endeavours.

4. Teachers did not comment on epistemic aspects, the development of evidence-based explanations and the critical evaluation of alternative views when discussing the benefits of IBL.

5. The role of the teacher in providing guidance is important.

6. Teachers in this study expressed frustration with their experiences, the lack of time, resources to prepare for IBL, managing group work and the demands of curriculum delivery, assessment and accountability.

7. Teacher education and professional development could support teacher change, understanding of curriculum resources and experience of IBL.

Teachers in the 'England' sample were positive about inquiry-based science education as these data show (Figure 2a), with participants identifying benefits to students, teachers and teaching using IBL. They recognised its value and would like to 'teach in this way' more often. Teachers reported high levels of using IBL (94.4\%) in their teaching with a smaller number using student research projects in their classrooms $(39.3 \%)$ as we can see in Figure 4 .

Spanish teachers (Figure $\mathbf{2 b}$ ) exhibited very similar views of the effects of IBL and their orientation to use it, when compared to the English sample. 

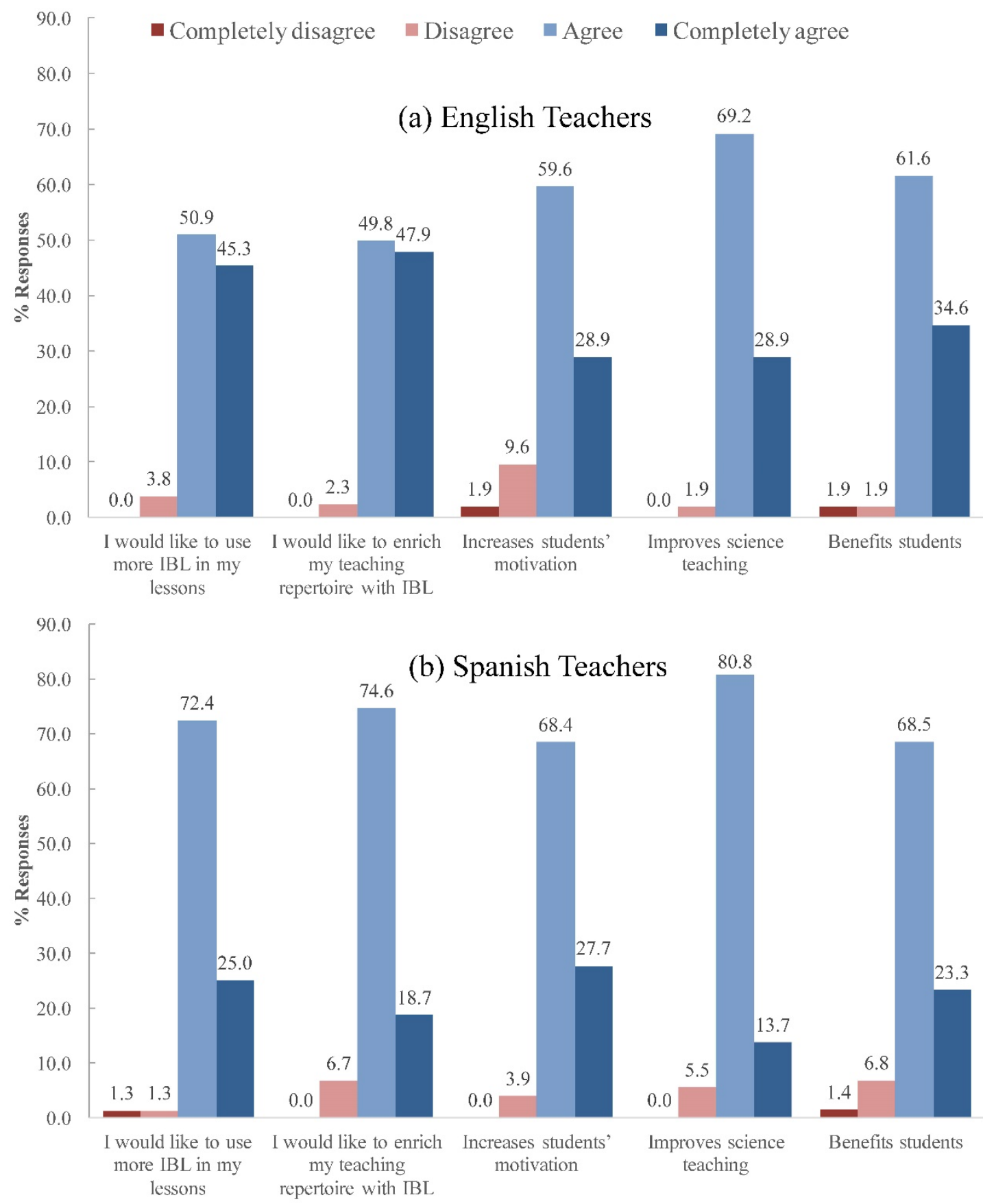

Figure 2. Teachers' views of IBL

Taking together the 'agree' and 'completely agree' categories, we can see that over ninety percent of Spanish teachers stated that IBL benefits their students, increases their motivation and improves science teaching. Most of them agree or completely agree that they would like to enrich their teaching repertoire $(93.3 \%)$ and use more IBL in their lessons $(97.4 \%)$. Similar to English teachers, the Spanish teachers in our sample showed an extremely positive orientation to the use of IBL.

Along with teachers' views and dispositions to use IBL in their classroom, the survey also explored their perception of barriers and obstacles, showing again a high level of similarity between the English and the Spanish samples (Figure 3). 

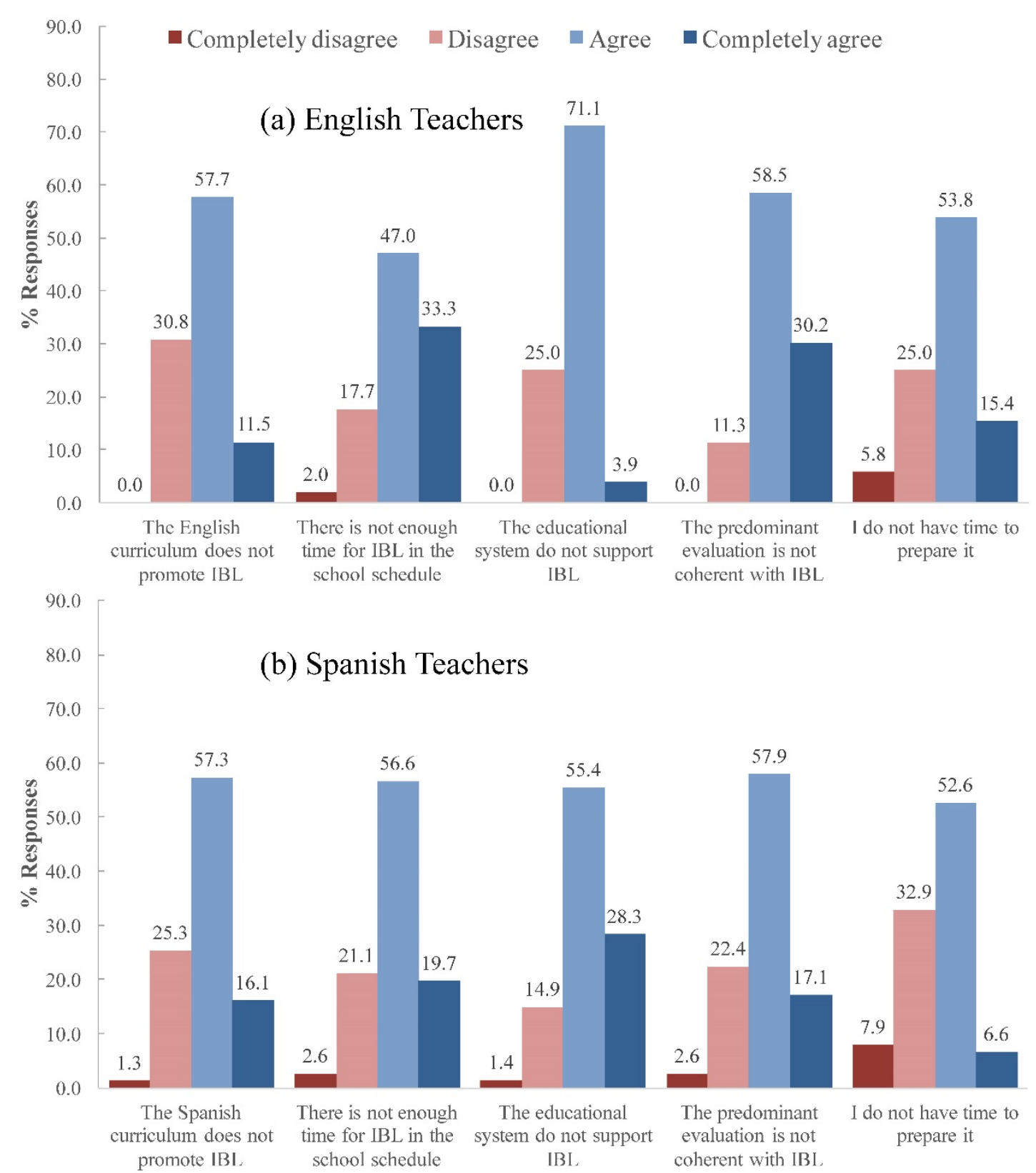

Figure 3. Teachers' views of barriers to the implementation of IBL in daily teaching

Spanish teachers claim that the educational system does not support IBL (83.7\%) and time (76.3\%) and assessment $(75.0 \%)$ are considered important obstacles. Likewise, English teachers identify time (80.3\%) and assessment $(88.7 \%)$ as major barriers for a wider use and $75.0 \%$ agree or completely agree that the English educational system does not support IBL.

In spite of the similarities concerning their disposition to use IBL in the classroom and their perception of constraints and barriers, our survey revealed important differences. While (94.4\%) of the English teachers reported using IBL in their classrooms, only $24.0 \%$ of the Spanish did.

Figure 4 shows important differences in the use of IBL between English and Spanish teachers, but also in the way both samples envisioned their enactment. 96.1\% of Spanish teachers found it difficult to manage group work, versus just $37.7 \%$ of English teachers and the availability of inquiry materials was a bigger problem for Spanish teachers than for English ones. Additionally, almost $64.5 \%$ of Spanish teachers reported using problems with clear and correct answers while less than a half (48.2\%) of English teachers agreed with this statement (Figure 4). This suggests a different view of the kind of problems posed and clarification of the role of teachers when supporting students to reach a solution. 


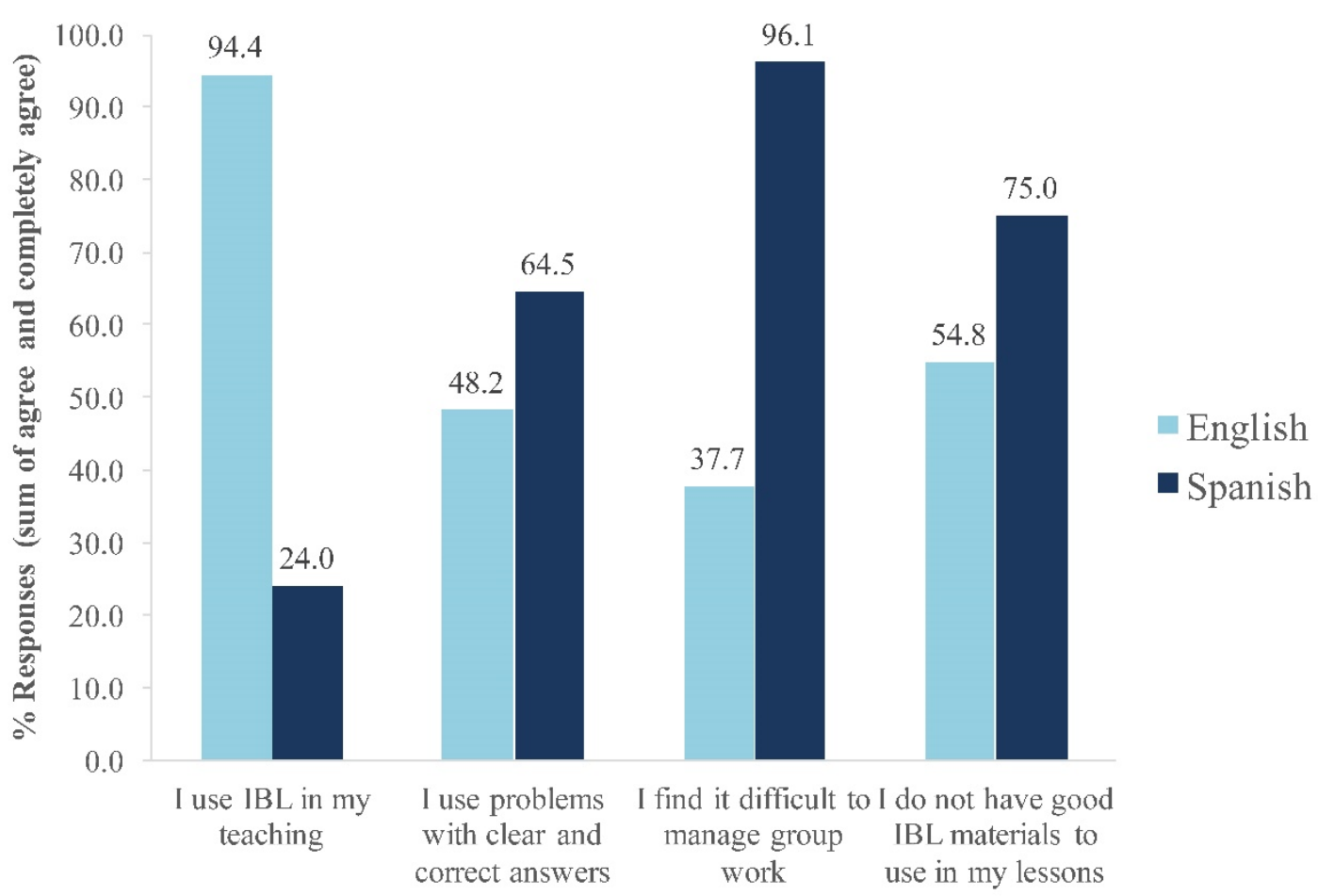

Figure 4. Main differences between English and Spanish teachers' views about IBL

The qualitative analysis of the interviews and group discussions in both countries offered an in-depth view of how Spanish and English teachers conceptualised IBL. In presenting these findings, we have identified the themes that emerged in relation to each of the research questions. We have presented the results in a unified manner as the content analysis of the interviews and focus group discussions shows a consistent vision of IBL in both countries, with similarities among pre- and in-service teachers. This picture has been built through meaningful references to teachers' previous experiences and how they describe IBL enactment and its effects on students' engagement and learning.

In relation to the first research question, participants in the interviews and the focus group discussions (FGD1 and FGD2) spoke about inquiry as being collaborative, open-ended, relevant, engaging and motivating, with a potential to develop both conceptual understanding and skills. They described IBL as "investigations with no recipe, but a certain structure". They were positive and supportive in that, "inquiry helps them understand what they are doing and why they are doing it". Although the teachers in our studies were claiming that IBL had the potential to support learning in various ways, they did not focus on the particular components of the IBL approaches and their own practices that were likely to be most supportive of this. They spoke of students better understanding concepts when they learn in a practical (manipulative) way but did not refer to other cognitive or epistemological aspects shown to have a positive impact on learning (Furtak et al., 2012; Minner et al., 2010). Therefore, outcomes from our study suggest that even teachers with sophisticated views of IBL mainly focus on inquiry as investigation, but with low emphasis on the building of explanatory models, and the evaluation of alternative explanations in the light of evidence.

To address the second research question, teachers reported on their experiences in the classroom using IBL. In order to make the most of open-ended tasks, all English participants in the interviews noted that guidance was an important part of the decision making for the teacher, with a balance between too much structure and an open approach. Commenting on his experience with IBL, one teacher noted points where he felt activities needed to be "longer [with] more structure" (English pre-service), especially in supporting some students in focusing on the conceptual development aspect of activities. However, the importance of leaving space to "have a go" and "explore" was noted. English teachers expressed "surprise" and talked about the way the students "had gone beyond normal expectations" when using IBL. This was re-iterated in both pre- and in-service teachers in Spain during the focus group discussions: "and they may surprise you, actually they always surprise you" (in-service Spanish teacher, FGD1); "actually, you are stimulating their creativity and once you do that, they can take thousands of different routes" (pre-service Spanish teacher, FGD2). 
Furthermore, when discussing how to support students' work, collaboration appeared as a critical element:

Inquiry-based learning should be implemented in a collaborative way to allow students to support each other...furthermore, you realise that when someone gets lost, there is always somebody who can move on, and then their discussion and feedback make them keep on track (in-service Spanish teacher, FGD1).

There is not just interaction between the members of a group, but also among groups ...we have done so, but we did it in a different way... they exchange ideas (pre-service Spanish teacher, FGD2).

The emphasis on collaboration was clearly reflected in the way the English teachers described effective IBL practices during the interviews, with one in-service teacher seeing "working as a team" as an important element. Collaboration, discussion and metacognitive questioning can be promoted and used in IBL classrooms where students "provide explanations and reasons to make their thinking more explicit" (Gillies et al., 2014, p. 127). These features can be taught to students and teachers.

In order to encourage students' engagement and autonomy, English teachers referred to the need to build an appropriate classroom atmosphere giving "the security that there was no right or wrong answer" and one the Spanish in-service teacher mentioned that "overall you have to facilitate students' self-confidence, make them feel that they can safely make their arguments and develop solutions". This finding resonated with research reporting positive associations between IBL and engagement (for example, McConney et al., 2014).

With respect to the enactment of inquiry in classes, teachers spoke of the potential of IBL to provide relevance and authenticity to students even though teaches in both countries are expected to use local contexts and highlight relevance and meaning for everyday life as part of their teaching. It was suggested that IBL could be motivating, with context-based learning and the application of knowledge, "being able to apply that to what we are doing in class is really important to my students' understanding ... why it is useful skill we are using" (in-service English teacher).

I noticed that they really enjoy using knowledge to explain daily phenomena. That was the case when we tried to answer the question about what happens to taste buds if you have something very hot. They want learning to be connected to something close and meaningful to them (pre-service Spanish teacher, FGD2).

I was surprised that they had learned anything, having not been teaching, but not only had they come out with understanding of the yield, the purity and the importance of the environmental factors to consider in mining, I think they also developed some skills ....apply it to a real-world situation (in-service English teacher).

Teachers also talked about how inquiry helped students to develop conceptual understanding through being more actively involved with ideas in relevant contexts, such as

That year I worked with foci of interest, with topics close to students and their neighbourhood, the main square in their village... we worked with real data (in-service Spanish teacher, FGD1).

If you introduce the concept of units in a traditional way, do students get the physical meaning of what a metre is? But if you ask them to get a metre in the classroom and you provide them with no rule or any other tool, and they have to search and look for references and strategies, they will build a physical meaning through manipulation (in-service Spanish teacher, FGD1).

Teachers also recognised the importance of finding an appropriate amount of guidance to students. As one participant said, "the teacher must not tell the solution but say something to help students' thinking" (pre-service Spanish teacher, FGD2) though, generally, in-service Spanish teachers spent more time discussing how to structure and guide those activities, "I need to plan the hints not the process" (in-service Spanish teacher, FGD1). Teachers showed their skill at keeping students focused on a direction. For example,

Sometimes working with open-ended tasks makes it less precise, I mean unpredictable, therefore, it is essential to keep in mind where you want students to get (in-service Spanish teacher, FGD1). 
I think it must be done in a way such that the students don't lose sight of their primary aim of that sequence of lessons (in-service English teacher, FGD1).

I cannot miss the goal, I have to ensure that students meet the objectives, if not, it takes an eternity...I mean, I have to control it, let it open but also controlled (in-service Spanish teacher, FGD1).

This focus on achieving cognitive learning outcomes was supported by experienced teachers in contrast to the pre-service teachers' enthusiasm for open-ended inquiry and may well be reflective of the more experienced teachers' greater awareness of accountability, and hence the practicalities of enacting and enabling inquiry to meet particular measurable outcomes. In summary of the positive views expressed and experiences of inquiry, our qualitative analysis shows that participants exhibited the perception of IBL as open-ended investigations, though recognising the key role of teachers' guidance to support students' productive work.

In response to research question three, participants volunteered and elaborated on the barriers and constraints to IBL. Participants were clear that the use of IBL approaches generally remained low nationally, despite its presence in national curricula and the repeated efforts to promote these pedagogies. All the main challenges identified in the survey data were reiterated in the interviews and focus groups. The challenges and constraints were identified as being resources (materials and time), curriculum structure, assessment, accountability, collegiality and cooperation between teachers, and professional development. One teacher summarised this in the interview,

It's not as easy as delivering material in a didactic way, so obviously work has to be put in $[\ldots]$ a lot of that has to come down to convincing teachers to get on board and invest their time in developing the necessary resources ... also you've got to open up the challenges that come within the delivery and the teaching of it (in-service English teacher).

Time emerged as a major constraint for teachers, in terms of coping with a content-laden curriculum, preparation and resourcing, along with other pedagogical challenges.

Conducting inquiry in the classroom takes much time; one hour it is not enough unless you think of something really simple (pre-service Spanish teacher, FGD2).

You must know that allowing students to manipulate and investigate on their own takes time (in-service Spanish teacher, FGD1).

If taking such approaches serves only to provide some interesting lessons then it probably can't fit within the economics of our teaching time (in-service English teacher, FGD1).

Additionally, it was claimed that more teachers would use inquiry if they had more good materials and resources to use and adapt, "maybe they would like to do it but the issue is that they have never done it and they do not have good projects to implement or good examples to follow" (pre-service Spanish teacher, FGD2).

All participants in the qualitative study noted assessment as one of the main reasons for not having a wider use of inquiry. While national curricula continue to have a stress on processes of science, underscoring the importance of inquiry, it was felt that the assessment arrangements did not reflect this emphasis. Even where assessment was positioned as concerned with aspects of inquiry it was not seen as such, but rather that the approach was "we'll assess one thing as skills independently of the others" (pre-service English teacher). Likewise, in Spain, "Because there are exams but inquiry is not supposed to be assessed through exams (...) the problem is that exams are predominant in the current educational system" (pre-service Spanish teacher, FGD2).

When asked in the interview why she felt that inquiry did not feature strongly, the teacher simply laughed and shook her head before stating:

Because of the examinations the restraints on [teachers] in order to get this much taught by this point, you need to go through content first. It's not built into the schemes of work we teach, it's not necessarily promoted... we talk about examinations and although it's touched upon...it's very, very small... I don't think is assessed (in-service English teacher).

When discussing assessment, in-service Spanish teachers also recognised that inquiry requires a different evaluation approach, which is not usually aligned with the predominant assessment system. One of the teachers, after commenting on his effort to use inquiry approaches in the classroom stated: "Finally I sat down and said to myself let's wait for the evaluation results, but since I used a conventional assessment it turn out as a complete disaster" (in-service Spanish teacher, FGD1). 
Therefore, teachers in both countries seemed to recognise the value of adopting more IBL approaches but felt that there was a general lack of valuing of IBL in the system, as reflected in the national testing arrangements. English teachers also claimed that the OFSTED inspection emphasis had also worked against this, with its attendant high stakes in terms of accountability, if observed using IBL approaches and head teachers and senior leaders in schools reflected this concern in judging their teaching.

The need for teacher collaboration was seen to be an important factor in developing IBL approaches. However, opportunities for teachers to collaborate and share lesson planning and development were seen as limited and hence served to constrain innovation. This has implications for in-service professional development. Both pre- and in-service Spanish teachers paid importance to enlisting the support of the head of the school and other colleagues when trying to use inquiry approaches in the classroom. Some in-service teachers claimed feeling "alone" when trying to introduce innovative methods in the classroom, while others refer to common projects carried out by a team of teachers as a really enriching and rewarding experience, "It is much harder to do it alone, when compared to doing it as part of a team working in the same direction" (in-service Spanish teacher, FGD1).

Although these in-service teachers place much emphasis on the importance of collaboration and teamwork among teachers to facilitate the implementation of innovations, they also claimed that Spanish teachers in general, are not used to collaborating with each other.

Finally, teacher education and professional development were also mentioned as obstacles for not having a wider use of inquiry. Pre-service teachers consider that in-service teachers lack experience, referents and specific training in these methods and they should keep on learning and updating their knowledge and skills throughout their life, while in-service teachers suggest that these pedagogies should be promoted from initial teacher education.

\section{DISCUSSION}

In this section, we reflect on the results presented above and discuss these in the light of views of IBL, the enactments of IBL, the barriers and constraints to IBL and the goals of inquiry in science education.

Teachers' responses show a view of IBL enactment as a motivating and collaborative learning process where students are engaged in open-ended tasks guided by teachers. Of note, teachers offered positive aspects of IBL as tending towards the affective and procedural rather than articulate positive cognitive or explanatory aspects. They recognise how practical activities and manipulation enhance students' motivation, engagement and understanding. Teachers in England were aware of the Maintaining Curiosity report (Lievesley, 2014) and the more positive messages about IBL contained within it. In this study, there is a tension between teachers' positive views of inquiry and the reticence expressed over the enactment of inquiry. In part, this may be due to a prevailing perception as inquiry being "hands on" and activity-rich classroom investigation, rather than the more sophisticated model described above. Lederman et al. (2013) articulated further issues with such perceptions:

It is important to emphasise that we should no longer assume that students will come to understand NOS or scientific inquiry as a by-product of 'doing' science-based or inquiry activities. Nor should we assume that if teachers understand NOS and scientific inquiry, they will automatically teach in a manner 'consistent' with those understandings. NOS and scientific inquiry should be thought of as a 'cognitive' rather than as an 'affective' instructional outcomes (p. 144).

This further supports an argument to move from an emphasis on behavioural outcomes, or knowing more about "what scientists do", to that of cognitive and epistemic aspects. This means creating a challenge that cognitively engages students within a practical context, focusing on student problem-solving, reflection on thinking and metacognition. Indeed, many argue that improving questioning in inquiry classrooms is essential for guiding and scaffolding student thinking (Kawalkar \& Vijapurkar, 2013).

How then to support the development of the teachers' practice in the effective use of IBL? The identification of constraints is the first step in the search for more effective ways to support teachers in making the most of this pedagogy, both from an individual perspective (teacher professional development and teachers' collaboration) and from a systemic one (curricular standards, school organisation and assessment). However, while the evidence reviewed here suggests a need to develop thinking on the type of inquiry to be promoted, it is clear that most teachers believe in the value and importance of developing the use of IBL approaches. Why then is it relatively little used, and what might be done about this?

These data show that one issue concerned the perceived lack of emphasis given to IBL in both initial teacher preparation and in-service professional development. The issue of the demands of teaching in this manner points to the importance of exploring this. Crawford's (2000) noted that working in this way, 
suggests a myriad of constantly changing teacher roles that demands more active and complex participation than that suggested by the commonly used metaphor, teacher as facilitator. If we are to avoid the failures of our past related to giving teachers teacher-proof curriculum, we need to turn our attention to how best to support teachers in embracing the essence of inquiry (p. 935).

This suggests that there needs to be a much clearer attention given to the development of pedagogical practice. Without this commitment to professional development, it is difficult to see how the kinds of models suggested by the NRC (2012) and advocated by the European Commission (2015) would be put into practice. Our data also suggest that our teachers see collaboration as an important factor in supporting developments in practice and this needs to be included as part of teacher development processes.

Data presented here highlighted systemic issues. Many teachers reported difficulty in resourcing appropriate activities, finding time and managing the classroom to support IBL. They expressed concerns about the curriculum time, learning objectives and assessment. Given the emphasis on inquiry from policy makers, teacher educators and researchers, this is concerning. How do teachers juggle the competing demands of using a more inquiry approach and covering the curriculum content in a manner that prepares the students for their key examinations?

Concerns about assessment clearly emerged in discussions with teachers. It was clear that the nature of the assessment and accountability systems in both countries were seen to be unsupportive of a wider use of IBL. In this line, Crawford (2014) claims that the current assessment tools "fall short of what is needed to provide a good account of students' achievement and the goals of IBSE" (p. 4). Findings from this study suggest the need to review the assessment system so it is better aligned with the pedagogies being promoted and including more explicit aspects of epistemic inquiry in assessment.

In considering teachers' views of IBL, we explored how consistent these were with the three-sphere model discussed by Osborne (2014) and reflected in the science education standards (NRC, 2012). A pedagogy aligned with this model of science education ideally articulates three key processes: investigating, constructing explanations and evaluating results to ensure consistency between evidence and theories or models (see Figure 1). Although teachers referred to IBL as students developing their own solutions through investigative and manipulative processes, there was no emphasis on the evaluation of alternative views and explanations and the role of argumentation and modelling in science and in science education. These findings support the findings of Capps et al. (2016), who identified a gap in self-reported frequency and knowledge about inquiry in science teachers. This raises the questions of what constitutes inquiry?

Thus, there is a need to equip teachers with a good understanding of key learning outcomes in science education and a critical reflection on what kind of (or aspects of) IBL supports those learning goals. IBL could be better conceptualised as "teachers engaging students in questioning, modelling and communicating" ideas (Capps et al., 2016, p. 955) rather than some of the affective items that teachers identified in this study. This will require greater efforts on the parts of science educators and those preparing the next and current generation of science teachers to more carefully articulate and evidence claims about IBL. Additionally, assessment pressures on teachers and accountability are barriers to successful implementation. The need for teachers' to "cover the curriculum" presents an opportunity to design-led innovators to support teachers' classroom practice.

\section{CONCLUSIONS AND IMPLICATIONS}

The combination of both quantitative and qualitative data in a study across two European countries (UK and Spain) offered an interesting picture of teachers' views concerning the use of inquiry approaches.

Participants highlighted the effects of IBL on students' motivation and engagement and referred to the positive impact of hands-on and manipulative experiences on learning. However, they did not refer to further cognitive or epistemic aspects, which are at the heart of current interpretations of inquiry in science education (Capps et al., 2016; NRC, 2012; Osborne, 2014). Additionally, teachers said that they would like to use more IBL, but discussed tensions between this pedagogy and current curricula and assessment methods. They claimed for further systemic support and specific teacher training in this area and pointed out at the need to strengthen teacher collaboration in the implementation of innovations.

Taking the three spheres model as a referent to interpret these results (NRC, 2012), our study reveals that teachers emphasise the investigation component of inquiry over the dimensions concerning the development and evaluation of explanatory models. It suggests the need to further work on the dimensions related to explaining and evaluating when conceptualising and enacting inquiry in the classroom. Therefore, outcomes demonstrate that there is limited use of these approaches, and that understandings of the goals and pedagogical issues are still unclear. The study highlights need to clarify the purposes and aspects of IBL that are critical to its effective use coupled with initial teacher and in-service professional development. 


\section{LIMITATIONS}

This study does not strive for statistical generalisation from sample to population, but to an analytical one (Plomp, 2013), relying on the quality criteria of qualitative research, since the focus is on developing a rich picture and an in-depth understanding. This is a small-scale study with in a population of teachers already positively inclined to IBL. The findings may not be generalisable or applicable to other countries, or even to groups of science teachers in England and Spain. After decades of political efforts to promote IBL, this study contributes to the discussion of the different kinds of inquiry, contrasting teachers' views with science education standards and current interpretations of how inquiry should be operationalised to maximised its benefits on learning.

\section{REFERENCES}

Abd-El-Khalick, F., BouJaoude, S., Duschl, R., Lederman, N. G., Mamlok-Naaman, R., Hofstein, A., ... Tuan, H.-l. (2004). Inquiry in science education: International perspectives. Science Education, 88(3), 397-419. https://doi.org/10.1002/sce.10118

Alfieri, L., Brooks, P. J., Aldrich, N. J., \& Tenenbaum, H. R. (2011). Does discovery-based instruction enhance learning? Journal of Educational Psychology, 103, 1-18. https://doi.org/10.1037/a0021017

Ariza, M. R., Aguirre, D., Quesada, A., Abril, A., \& García. F. J. (2016). Wool or metal? Inquiry Based Learning on the thermal properties of common materials (¿Lana o metal? Una propuesta de aprendizaje por indagación para el estudio de las propiedades térmicas de materiales comunes). Revista Electrónica de Enseñanza de las Ciencias, 15(2), 297-311.

Asay, L. D., \& Orgill, M. K. (2010). Analysis of Essential Features of Inquiry Found in Articles Published in The Science Teacher, 1998-2007. Journal of Science Teacher Education, 21, 57-79. https:/ / doi.org/10.1007/s10972009-9152-9

Buehl, M. M., \& Beck, J. S. (2015). The relationship between teachers' beliefs and teachers' practices. In H. Fives \& M.G. Gill (Eds.), International handbook of research on teachers' beliefs (pp. 66-84). New York: Routledge.

Capps, D. K., \& Crawford, B. A. (2013). Inquiry-Based Instruction and Teaching About Nature of Science: Are They Happening? Journal of Science Teacher Education, 24, 497-526. https:/ / doi.org/10.1007/s10972-012-9314-Z

Capps, D. K., Shemwell, J. T., \& Young, A. M. (2016). Over reported and misunderstood? A study of teachers' reported enactment and knowledge of inquiry-based science teaching. International Journal of Science Education, 38(6), 934-959. https:/ / doi.org/10.1080/09500693.2016.1173261

Charmaz, K., \& McMullen, L. M. (2011). Five ways of doing qualitative analysis: Phenomenological psychology, grounded theory, discourse analysis, narrative research, and intuitive inquiry. New York: Guilford Press.

Crawford, B. A. (2000). Embracing the Essence of Inquiry: New Roles for Science Teachers. Journal of Research in Science Teaching, 37(9), 916-937. https:/ / doi.org/10.1002/1098-2736(200011)37:9<916::AID-TEA4>3.0.CO;22

Crawford, B. A. (2014). From Inquiry to Scientific Practices in the Science Classroom. In Lederman, N. G., \& S. K. Abell, S. K. (Eds.), Handbook of Research in Science Education (vol. II, pp. 515-541) New York: Routledge.

Creswell, J. W., \& Plano Clark, V. L. (2011). Designing and conducting mixed-methods research (2nd ed.). Thousand Oaks, CA: SGE Publications, Inc.

Donnell, L. A., \& Gettinger, M. (2015). Elementary school teachers' acceptability of school reform: Contribution of belief congruence, self-efficacy, and professional development. Teaching and Teacher Education, 51, 47-57. https:/ / doi.org/10.1016/j.tate.2015.06.003

Duschl, R. A., \& Bybee, R. W. (2014). Planning and carrying out investigations: an entry to learning and to teacher professional development around NGSS science and engineering practices. International Journal of STEM Education, 1(1), 12. https:/ / doi.org/10.1186/s40594-014-0012-6

Engeln, K., Euler, M., \& Maass, K. (2013). Inquiry-based learning in mathematics and science: a comparative baseline study of teachers' beliefs and practices across 12 European countries. ZDM, 45(6), 823-836. https:/ / doi.org/10.1007/s11858-013-0507-5

European Commission (2007). Science Education Now. A renewed pedagogy for the future of Europe. Luxembourg: Offices for Official Publications of the European Communities. Retrieved from http:/ / ec.europa.eu/research/science-society/document_library/pdf_06/report-rocard-on-scienceeducation_en.pdf.

European Commission (2015). Science Education for Responsible Citizenship. Luxembourg: Offices for Official Publications of the European Communities. Retrieved from http:/ / ec.europa.eu/research/swafs/pdf/pub_science_education/KI-NA-26-893-EN-N.pdf 
Forbes, C. T., \& Davis, E. A. (2010). Curriculum design for inquiry: Pre-service elementary teachers' mobilization and adaptation of science curriculum materials. Journal of Research in Science Teaching, 47(7), 820-839. https:/ / doi.org/10.1002/tea.20379

Furtak, E. M., Seidel, T., Iverson, H., \& Briggs, D. C. (2012 online). Experimental and Quasi-Experimental Studies of Inquiry-Based Science Teaching. Review of Educational Research, 82(3), 300-329. https:/ / doi.org/10.3102/0034654312457206

Gillies, R. M., Nichols, K., Burgh, G., \& Haynes, M. (2014). Primary students' scientific reasoning and discourse during cooperative inquiry-based science activities. International Journal of Educational Research, 63, 127-140. https:/ / doi.org/10.1016/j.ijer.2013.01.001

Glackin, M. (2016). 'Risky fun' or 'Authentic science'? How teachers' beliefs influence their practice during a professional development programme on outdoor learning. International Journal of Science Education, 38(3), 409-433. https:/ / doi.org/10.1080/09500693.2016.1145368

Hattie, J. (2009). Visible learning: a synthesis of meta-analyses relating to achievement. Abingdon, Oxon: Routledge. https://doi.org/10.4324/9780203887332

Herrington, D. G., Bancroft, S. F., Edwards, M. M., \&. Schairer, C. J. (2016). I want to be the Inquiry Guy! How Research Experiences for Teachers Change Beliefs, Attitudes, and Values About Teaching Science as Inquiry. Journal of Science Teacher Education, 27(2), 183-204. https:/ / doi.org/10.1007/s10972-016-9450-y

Hutner, T. L., \& Markman, A. B. (2016). Department-Level Representations: A New Approach to the Study of Science Teacher Cognition. Science Education, 100(1), 30-56. https:/ / doi.org/10.1002/ sce.21186

Jerrim, J., Oliver, M., \& Sims, S. (2019). The relationship between inquiry-based teaching and students' achievement. New evidence from a longitudinal PISA study in England. Learning and Instruction, 61, 35-44. https://doi.org/10.1016/j.learninstruc.2018.12.004

Kawalkar, A., \& Vijapurkar, J. (2013). Scaffolding Science Talk: The role of teachers' questions in the inquiry classroom. International Journal of Science Education, 35(12), 2004-2027. https:/ / doi.org/10.1080/09500693.2011.604684

Kirschner P. A., Sweller J., \& Clark R. E. (2006). Why minimal guidance during instruction does not work: An analysis of the failure of constructivist, discovery, problem-based, experiential, and inquiry-based teaching. Educational Psychologist, 41, 75-86. https:/ / doi.org/10.1207/s15326985ep4102_1

Krämer, P., Nessler, S. H., \& Schlüter, K. (2015). Teacher students' dilemmas when teaching science through inquiry. Research in Science E Technological Education, 33(3), 325-343. https:/ / doi.org/10.1080/02635143.2015.1047446

Lazonder, A. W., \& Harmsen, R. (2016). Meta-Analysis of Inquiry-Based Learning Effects of Guidance. Review of Educational Research, 20(10), 1-38. https:/ / doi.org/10.3102/0034654315627366

Lebak, K. (2015). Unpacking the Complex Relationship Between Beliefs, Practice, and Change Related to InquiryBased Instruction of One Science Teacher. Journal of Science Teacher Education, 26(8), 695-713. https:/ / doi.org/10.1007/s10972-015-9445-0

Lederman, N. G., Lederman, J. S., \& Antink, A. (2013). Nature of Science and Scientific Inquiry as Contexts for Learning of Science and Achievement of Scientific Literacy. International Journal of Education in Mathematics, Science and Technology, 1(3), 138-147.

Lee, E. A., \& Brown, M. J. (2018). Connecting Inquiry and Values in Science Education. Science \& Education, 27(1-2), 63-79. https:/ / doi.org/10.1007/s11191-017-9952-9

Lievesley, T. (2014). What Does OFSTED Say? Primary Science, 133, 22-23.

Maaß, K., \& Engeln, K. (2016). Report on the large-scale survey about inquiry-based learning and teaching in the European partner countries. EUproject mascil, Deliverable No 10.2.

McConney, A., Oliver, M. C., Woods-McConney, A., Schibeci, R., \& Maor, D. (2014). Inquiry, Engagement, and Literacy in Science: A Retrospective, Cross-National Analysis Using PISA 2006. Science Education, 98(6), 963980. https:// doi.org/10.1002/sce.21135

Minner, D. D., Levy, A. J., \& Century, J. (2010). Inquiry-Based Science Instruction - What Is It and Does It Matter? Results from a Research Synthesis Years 1984 to 2002, Journal of Research in Science Teaching, 47(4), 474-496. https:/ / doi.org/10.1002/tea.20347

National Research Council (2012). A Framework for K-12 Science Education: Practices, Crosscutting Concepts, and Core Ideas. Washington, DC: The National Academies Press.

OECD (2017). 'PISA 2015 Science Framework', in PISA 2015 Assessment and Analytical Framework: Science, Reading, Mathematic, Financial Literacy and Collaborative Problem Solving, OECD Publishing, Paris. https:/ / doi.org/10.1787/9789264281820-3-en 
OFSTED (2013). Office for Standards in Education, Children's Services and Skills. Retrieved from https://www.gov.uk/government/uploads/system/uploads/attachment_data/file/386795/Ofsted_Ann ual_Report_201213_Schools.pdf

Önder, F., Şenyiğit, Ç., \& Sılay, İ. (2018). Effect of an inquiry-based learning method on students' misconceptions about charging of conducting and insulating bodies. European Journal of Physics, 39(5), 055702. https:/ / doi.org/10.1088/1361-6404/aac52a

Osborne, J. \& Dillon, J. (2008). Science Education in Europe: Critical Reflections. Nuffield Foundation. Retrieved from http://www.nuffieldfoundation.org/sites/default/files/Sci_Ed_in_Europe_Report_Final.pdf

Osborne, J. (2014). Teaching scientific practices: Meeting the challenge of change. Journal of Science Teacher Education, 25(2), 177-196. https:/ / doi.org/10.1007/s10972-014-9384-1

Ozel, M., \& Luft, J. (2013). Beginning Secondary Science Teachers' Conceptualization and Enactment of InquiryBased Instruction. School Science and Mathematics, 113(6), 308-316. https:/ / doi.org/10.1111/ssm.12030

Plomp, T. (2013). Educational design research: An Introduction. In Plomp, T. \& Nieveen, N. (Eds.), Educational design research - Part A: An Introduction. Enschede, the Netherlands: SLO.

Rönnebeck, S., Bernholt, S., \& Ropohl, M. (2016). Searching for a common ground - A literature review of empirical research on scientific inquiry activities. Studies in Science Education, 52(2), 161-197. https:/ / doi.org/10.1080/03057267.2016.1206351

Schwarz, C. V., Gunckel, K. L., Smith, E. L., Covitt, B. A., Bae, M., Enfield, M., \& Tsurusaki, B. K. (2008). Helping elementary preservice teachers learn to use curriculum materials for effective science teaching. Science Education, 92(2), 345-377. https:// doi.org/10.1002/sce.20243

van Uum, M. S. J., Verhoeff, R. P., \& Peeters, M. (2016). Inquiry-based science education: towards a pedagogical framework for primary school teachers. International Journal of Science Education, 38(3), 450-469. https:/ / doi.org/10.1080/09500693.2016.1147660

Windschitl, M., Thompson, J., \& Braaten, M. (2008). Beyond the scientific method: Model-based inquiry as a new paradigm of preference for school science investigations. Science Education, 92(5), 941-967. https://doi.org/10.1002/sce.20259

\section{http://www.ejmste.com}

